Research article

\title{
Specific immunotherapy in Albanian patients with anaphylaxis to hymenoptera venoms
}

\author{
Ervin Mingomataj ${ }^{1,2}$, Alfred Priftanji ${ }^{1}$, Etleva Qirko1, Q Thai Dinh ${ }^{2}$, \\ Axel Fischer ${ }^{2}$, Christian Peiser ${ }^{2}$ and David A Groneberg*2
}

Address: ${ }^{1}$ Dept. of Allergy, Mother Theresa School of Medicine, University of Tirana, Tirana, Albania and 2Division of Allergy Research, Dept. of Pediatric Pneumology and Immunology, Charité School of Medicine, Humboldt-University, D-13353 Berlin, Germany

E-mail: Ervin Mingomataj - allergology@gmx.de; Alfred Priftanji - allergology@gmx.de; Etleva Qirko - allergology@gmx.de; Q Thai Dinh - qthai.dinh@charite.de; Axel Fischer - allergology@gmx.de; Christian Peiser - christian.peiser@charite.de;

David A Groneberg* - david.groneberg@charite.de

*Corresponding author

Published: 30 August 2002

BMC Dermatology 2002, 2:I I
Received: 25 April 2002

Accepted: 30 August 2002

This article is available from: http://www.biomedcentral.com/I47/-5945/2/I I

(C) 2002 Mingomataj et al; licensee BioMed Central Ltd. This article is published in Open Access: verbatim copying and redistribution of this article are permitted in all media for any non-commercial purpose, provided this notice is preserved along with the article's original URL.

Keywords: hymenoptera, Rush, Rush-SIT, anaphylactic reactions

\begin{abstract}
Background: Severe allergic reactions during rush-specific immunotherapy (Rush-SIT) may occur in the treatment of hymenoptera sting allergy. The objective of the present study was to examine the characteristics of allergic reactions during Rush-SIT in a cohort of patients with allergy towards hymenoptera venom in the mediterranean population of Albania.
\end{abstract}

Methods: A retrospective study was performed using the clinical reports of 37 patients with venom of bee (apinae), wasp (vespidae, subfamily vespinae) or paperwasp (vespidae, subfamily polistinae) allergy treated with Rush-SIT between 1987 and 1996. After hymenoptera sting allergy diagnosis according to anamnesis and intracutaneous tests the patient were treated with Rush-SIT. The protocol lasted $3-4 \mathrm{~d}$ with an increase in the concentration from $0.01 \mu \mathrm{g} / \mathrm{ml}$ to $100 \mu \mathrm{g} / \mathrm{ml}$. Anaphylactic reactions were classified according to the Mueller-classification.

Results: The frequency of reactions during Rush-SIT for bee-venom was $4.7 \%$ and for wasp-venom was $1.5 \%(p<0.01)$. The mean frequency of reactions of Mueller grade II for the bee-venom RushSIT patients during the first $4 d$ (= 26 injections) was 0.73 and for the wasp-venom Rush-SIT patients 0.15 . No patient experienced a third-degree reaction. $94.6 \%$ of the patient supported an end dose of $100 \mu \mathrm{g}$.

Conclusions: Rush-SIT is a reliable method for the treatment of anaphylactic reactions to hymenoptera venom even in less developed countries. Bee-venom Rush-SIT was found to cause higher numbers allergic reactions than wasp or paperwasp Rush-SIT.

\section{Background}

Anaphylactic reactions caused by hymenoptera stings predominantly bee, wasp or paperwasp - stings are a com- mon medical problem and account for approximately 40 deaths per year in the United Sates $[1,2]$. They belong to 
the most dramatic allergic diseases and may present with an acute onset of combined local and systemic symptoms.

The prevalence of insect-sting allergies varies between 0.4 to $4 \%$ and more [3-6], and the rate of mortality has been reported to be between 0.09 to $0.45 / 1000000$ people/year $[4,5,7]$.

It is generally accepted that these systemic reactions to insect stings, even if non-fatal, represent extremely unpleasant and dangerous situations. Therefore, many patients would benefit physically and psychologically from a preventive treatment. In general, the patients would prefer a long-term treatment rather than experiencing emergency medication and an everlasting fear about upcoming events. However, in consideration of the relatively low mortality rate reported, many physicians do not refer the patients to further detailed investigations. The presently available preventive treatment in form of specific immunotherapy is therefore often neglected. Also, a lack of knowledge of immunotherapy or limited access may be additional factors.

Apart from fire ants and mosquitoes in America, the suborder of hymenoptera aculeatae accounts for most allergic reactions in Europe $[8,9]$. A large number of studies on the prevalence and mortality of anaphylactic sting reactions, the differentiation between venoms and the impact of specific immunotherapy have been performed for industrialized western countries so far. However, hymenoptera allergies have been recognized as a worldwide health hazard, reaching also the developing countries but detailed studies for these regions have not been reported so far. In this respect, the present study was conducted to investigate the impact of Rush-SIT in a population of Albanian hymenoptera allergy patients which were treated with Rush-SIT.

\section{Methods}

Subjects

The present cohort consists of files collected from 37 patients who were treated with Rush-SIT for hymenoptera sting allergy at the university hospital of Tirana between the period of 1987 to 1996 . All study subjects were native Albanians. Before 1987, all patients were treated with whole body extracts and therefore excluded from the study.

\section{Evaluation of subjects}

For the assessment of the patients' history, general data (sex, age), the age when the sting reactions happened, time of stinging (date or month), place of stings, number of sting-episodes, identity of insect (if possible), and symptoms after sting episode were evaluated.

\section{Tests}

The tests consisted of intracutaneous tests in concentrations of $0.001,0.01,0.1$ and $1 \mu \mathrm{g} / \mathrm{ml}$ venom from bees (apinae), wasps (vespidae, subfamily vespinae) or paperwasps (vespidae, subfamily polistinae). Positive test results were accepted from induration diameters of at least $5 \mathrm{~mm}$.

\section{Specific rush immunotherapy (Rush-SIT)}

The Rush-SIT treatment was performed during a 4-day hospital stay, in which a standardized scheme of escalating doses of venom was administered subcutaneoulsy: The doses were increased from $10^{-2}$ to $100 \mu \mathrm{g} / \mathrm{ml}$ of venom (Table 1 ). The patients in the present study only received a single venom type, and subcutaneous maintenance injections of $100 \mu \mathrm{g}$ venom were performed after $7 \mathrm{~d}, 14 \mathrm{~d}$ and monthly for a period of 3 years.

In case of subjective or objective adverse reactions, the further treatment was dependent on the type of reaction as previously described [10]: Mild subjective reactions were followed by the application of the same dose before an increase. Objective reactions were followed by treatment of the symptoms and a period of one day without further venom application before starting with a reduced dose.

\section{Anaphylactic reactions}

Anaphylactic reactions during Rush-SIT were classified according to the criteria of Mueller into 4 degrees [11]:

\section{Statistics}

Data correlations were analyzed using the statistical method of Spearman. For direct data comparison the $\chi^{2}$-test was used.

\section{Results}

In total, 37 patients (23 male, 14 female) with an average age of 28 years were treated with Rush-SIT against bee venom $(59.5 \%)$, paperwasp venom $(5.4 \%)$ and wasp venom (35.1\%). According to their history, $91.9 \%$ of patients were admitted to the unit after experiencing an anaphylactic reaction (35.1\% Mueller type II and 56.8\% Mueller type III-IV) and $8.1 \%$ was treated after a mild skin reaction (Mueller type I) (Table 2). The skin tests defined the diagnosis through intracutaneous test at concentrations of $0.01 \mu \mathrm{g} / \mathrm{ml}$ (32.4\%), $0.1 \mu \mathrm{g} / \mathrm{ml}(64.9 \%)$ or $1 \mu \mathrm{g} / \mathrm{ml}$ (2.7\%) (Table 2).

During Rush-SIT,16 patients (43.2\%) experienced minor reactions. These reactions were present once in $25 \%$, twice in $18.75 \%$, three times in $18.75 \%$ and more than three times in $37.5 \%$. The reactions were found in $54.5 \%$ of patients treated with bee venom and in $30.8 \%$ in patients treated with wasp venom (no significance, n. s.) (Table 3 ). The mean frequency of reactions/injections was $3.4 \%$ (33 
Table I: Scheme of venom rush immunotherapy. The Rush-SIT treatment was according to a 4-day scheme with increasing doses of I0 -2 to $100 \mu \mathrm{g} / \mathrm{ml}$ of venom.

\begin{tabular}{|c|c|c|c|c|c|c|c|}
\hline \multicolumn{4}{|l|}{ Day I } & \multicolumn{4}{|l|}{ Day II } \\
\hline Time & Conc. $[\mu \mathrm{g} / \mathrm{ml}]$ & Volume [ml] & Quantity $[\mu \mathrm{g}]$ & Time & Conc. $[\mu \mathrm{g} / \mathrm{ml}]$ & Volume [ml] & Quantity $[\mu g]$ \\
\hline 08.30 & 0.01 & 0.05 & 0.0005 & 08.30 & 1.0 & 0.05 & 0.05 \\
\hline 09.00 & 0.01 & 0.10 & 0.001 & 09.00 & 1.0 & 0.10 & 0.1 \\
\hline 09.30 & 0.01 & 0.20 & 0.002 & 09.30 & 1.0 & 0.20 & 0.2 \\
\hline 10.00 & 0.01 & 0.40 & 0.004 & 10.00 & 1.0 & 0.40 & 0.4 \\
\hline 10.30 & 0.10 & 0.05 & 0.005 & 10.30 & 10.0 & 0.05 & 0.5 \\
\hline 11.00 & 0.10 & 0.10 & 0.01 & 11.00 & 10.0 & 0.10 & 1.0 \\
\hline 11.30 & 0.10 & 0.20 & 0.02 & 11.30 & 10.0 & 0.20 & 2.0 \\
\hline 12.00 & 0.10 & 0.40 & 0.04 & 12.00 & 10.0 & 0.40 & 4.0 \\
\hline 12.30 & 1.00 & 0.05 & 0.05 & 12.30 & 100.0 & 0.05 & 5.0 \\
\hline Day III & & & & Day IV & & & \\
\hline Time & Conc. $[\mu \mathrm{g} / \mathrm{ml}]$ & Volume [ml] & Quantity $[\mu \mathrm{g}]$ & Time & Conc. $[\mu \mathrm{g} / \mathrm{ml}]$ & Volume [ml] & Quantity $[\mu g]$ \\
\hline 08.30 & 100.0 & 0.05 & 5.0 & 08.30 & 100.0 & 1.00 & 100.0 \\
\hline 09.00 & 100.0 & 0.10 & 10.0 & & & & \\
\hline 09.30 & 100.0 & 0.20 & 20.0 & & & & \\
\hline 10.00 & 100.0 & 0.40 & 40.0 & & & & \\
\hline 10.30 & 100.0 & 0.60 & 60.0 & & & & \\
\hline 11.00 & 100.0 & 0.80 & 80.0 & & & & \\
\hline 11.30 & 100.0 & 1.00 & 100.0 & & & & \\
\hline
\end{tabular}

reactions per 962 injections). The same index for the bee venom was $4.7 \%$ and the one for wasp venom was $1.5 \%$ $(\mathrm{p}<0.01)$. The mean absolute frequency of first degree reactions for bee venom treated patients was 0.50 and the one for patients treated with wasp venom was 0.31 (n. s.). The same index for the second degree was 0.73 for bee venom treated patients and 0.15 for wasp venom treated patients with a significant difference of $\mathrm{p}<0.01$. Paperwasp treated patients experienced no anaphylactic reactions in the present study. Also, no Mueller type III or IV anaphylactic reaction was experienced. (Table 3).

The lowest dose causing a minor reaction was $5 \mu \mathrm{g}$ (type I), the lowest dose for anaphylactic reactions (type II) was $20 \mu \mathrm{g}$ with a peak at $60 \mu \mathrm{g}$ and no raise in frequency in higher concentrations (Figure 1).

These reactions were treated efficiently with adrenaline in $45.4 \%$, antihistamines in $21.2 \%$, with both in $15.2 \%$ and with costicosteroides (prednisolone) in combination with adrenaline and antihistamines in $3.0 \%$ of all cases. In $15.2 \%$ a treatment was not necessary. The use of epine- phrine in type II reactions was more frequent than in type I reactions $(20 \%$ of treated type I in contrast to $100 \%$ of type II $(\mathrm{p}<0.002)) .94 .6 \%$ of the patients supported the end dose $100 \mu \mathrm{g}$ venom.

\section{Discussion}

The first documented anaphylactic reaction towards hymenoptera venom was the death of the Egyptian pharaoh Menes, who died according to an Egyptian hieroglyph in the year $2640 \mathrm{BC}$ due to a wasp sting reaction [12], Since then, many treatment options were developed and tested. However, a specific preventive treatment has only been available since the pioneer works of Hunt et al. 1978. These studies demonstrated an almost complete protection by treatment with specific insect venom in contrast to earlier studies using whole body extracts which turned out to be equivalent to placebo [13].

The global extend of allergic diseases is still increasing with allergic diseases being a future threat even in developing countries,. However, only little is known on specific and preventive treatment in these countries due to eco- 
Table 2: Clinical data of patients who received stings I.

\begin{tabular}{ll}
\hline Number of patients & 37 \\
\hline & \\
Sex & \\
Males & $23(62.2 \%)$ \\
Females & $14(37.8 \%)$ \\
Middle age (years) & 28 \\
Range (years) & $8-52$ \\
Grade of sting ${ }^{*}$ & \\
I & $3(8.1 \%)$ \\
II & $13(35.1 \%)$ \\
III-IV & $21(56.8 \%)$ \\
Intra-cutaneous tests & \\
Lowest concentration eliciting the diagnosis & \\
$0.0 I$ ig/ml & $12(32.4 \%)$ \\
$0 . I \mu g / m l$ & $24(64.9 \%)$ \\
I $\mu g / m l$ & $1(2.7 \%)$ \\
Medication required & \\
Adrenaline & $15(45.4 \%)$ \\
Antihistamines & $7(21.2 \%)$ \\
Adr. + Antihist & $5(15.2 \%)$ \\
Both + Glucocorticoides & $I(3.0 \%)$ \\
No medication required & $5(15.2 \%)$ \\
& \\
\hline
\end{tabular}

\footnotetext{
* Classified according to Mueller [I I]: Grade I - urticaria, pruritus, malaise; Grade II - angioedema, chest tightness, nausea, vomiting, abdominal pain, dizziness; Grade III - dispnoea, wheeze, stridor, dysphagia, hoarseness; Grade IV - hypotension, collapse, loss of consciousness, incontinence, cyanosis.
}

nomical reasons. Here we studied the possibility and adverse reactions of specific immunotherapy in Europe's least developed country Albania, using hymenoptera Rush-SIT.

The efficacy of Rush-SIT is well documented [5,14,15], but adverse reactions including anaphylactic reactions have been reported in up to $64 \%$ of all cases investigated [1620].

Here we explored the occurrence of allergic reactions during Rush-SIT in a cohort of Albanian patients.

As immunotherapeutic scheme Rush-SIT was used, as this treatment form enables a hospital controlled administration of venom with a success of more than 95\% [21].

Even if $43.2 \%$ of the patients experienced reactions during Rush-SIT, which is in accordance to previous reports $[15,22]$, the percentage related to the number of injections is only $3.4 \%$.

Furthermore we found that during Rush-SIT, there was no significant difference of reactions/patient between bee venom and wasp venom treated patients in Mueller grade I. In

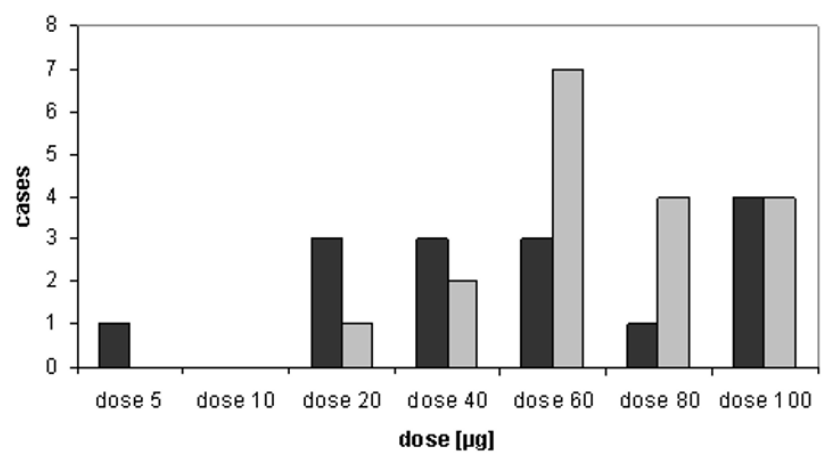

Figure I

Dose-dependency of reactions. The reactions were classiefied according to Mueller 10 with grade I - urticaria, pruritus, malaise; grade II - angioedema, chest tightness, nausea, vomiting, abdominal pain, dizziness; grade III - dispnoea, wheeze, stridor, dysphagia, hoarseness, and grade IV - hypotension, collapse, loss of consciousness, incontinence, cyanosis. Black: Mueller I, grey: Mueller II.

contrast, in Mueller grade II there was a significant difference between bee venom and wasp venom treated patients. In this respect, the bee venom was found to be more aggressive than the wasp venoms, as indicated earlier $[15,21]$.

Minor anaphylactic reactions (Mueller grade I - II) were present more frequent at the doses of 50 to $60 \mu \mathrm{g}$ and patients who did not experience reactions up to this dose, did not respond to higher doses later. This may be explained from the fact that the quantity of venom in a sting is about $50 \mu \mathrm{g}$ venom and an increased quantity such as the Rush-SIT end dose does not lead to an increased immune answer $[23,24]$.

For the therapy of allergic reactions during Rush-SIT, different drugs such as adrenaline, antihistamines or corticosteroides may be used. A possibility to prevent allergic reactions during Rush-SIT can be the preventive application of these drugs. Whereas adrenaline is suitable only for acute emergency medication in case of severe anaphylaxis, antihistamine medication only reduces cutaneous symptoms such urticaria effectively [25], but no anaphylactic situations. Therefore, the only efficient drugs for prevention anaphylaxis are corticosteroids which may be combined to antihistamines.

A recent retrospective study to determine the incidence and nature of adverse events associated with the induction of rush Hymenoptera venom immunotherapy in Australian patients demonstrated a high incidence of adverse systemic events during the induction phase [26]. Their conclusion, that immunotherapy should only be given by 
Table 3: Clinical data of patients who received stings II.

\begin{tabular}{|c|c|c|c|c|c|}
\hline & Total & Bee & Wasp & Paperwasp & $\mathrm{P} \#$ \\
\hline Number of patients & 37 & 22 & 13 & 2 & \\
\hline $\begin{array}{l}\text { Number of patients with allergic reactions during } \\
\text { immunotherapy }\end{array}$ & $16(43.2 \%)$ & $12(54.5 \%)$ & $4(30.8 \%)$ & 0 & NS \\
\hline Reactions/injections & $33(3.4 \%)$ & 27 (4.7\%) & $6(1.5 \%)$ & 0 & $<0.01$ \\
\hline \multicolumn{6}{|l|}{ Reactions/patients } \\
\hline $1^{*}$ & $15(40.5 \%)$ & II (50.0\%) & $4(30.8 \%)$ & 0 & NS \\
\hline II & $18(48.6 \%)$ & $16(72.7 \%)$ & $2(15.4 \%)$ & 0 & $<0.01$ \\
\hline III-IV & $0(0.0 \%)$ & $0(0.0 \%)$ & $0(0.0 \%)$ & 0 & \\
\hline
\end{tabular}

\# Statistical comparison between bee and wasp venom treated patients. * Classified according to Mueller[I I]: Grade I - urticaria, pruritus, malaise; grade II - angioedema, chest tightness, nausea, vomiting, abdominal pain, dizziness; grade III - dispnoea, wheeze, stridor, dysphagia, hoarseness; grade IV - hypotension, collapse, loss of consciousness, incontinence, cyanosis.

experienced staff in centres where there are facilities for resuscitation can be underlined by the present study. The therapy regimen should always be updated towards the standards published by internationally leading allergy centers.

\section{Conclusions}

In summary, the present study describes the first investigation on the use of specific immunotherapy in a developing country such as Albania and proves that this treatment option may also be used in non-industrialized countries with an adverse reaction profile similar to western countries.

\section{Competing interests}

None declared.

\section{Authors' contributions}

EM carried out the study and analyzed the results. AP examined the patients and initiated the study. EQ examined the patients. QTD participated in the statistical analysis AF analyzed the results and participated in the design of the study. CP performed the statistical analysis and participated in drafting the manuscript. DAG coordinated the study and prepared the draft.

All authors read and approved the final manuscript.

\section{Acknowledgements}

We thank A. Gerber, and V. Andoni and for help with entomological data, and D. Pleimes and B. Kloft for helpful discussions. Editorial help of $M$. Scheibner is also gratefully acknowledged. This study was supported by a grant (E.M.) of the European Academy of Allergology and Clinical Immunology $(\mathrm{EAACl})$.

\section{References}

I. Mosbech H: Death caused by wasp and bee stings in Denmark 1960-1 980. Allergy 1983, 38:1 195-200

2. Barnard JH: Studies of $\mathbf{4 0 0}$ Hymenoptera sting deaths in the United States. J Allergy Clin Immunol 1973, 52:259-264
3. Georgitis J, Reisman R: Venom skin tests in insect-allergic and insect-nonallergic populations. J Allergy Clin Immunol 1985, 76:803-807

4. Müller U, Mosbech H, Blaauw P, Dreborg S, Malling H, Przybilla B, Urbanek R, Pastorello E, Blanca M, Bosquet J, Jarisch R, Youlten L: Emergency treatment of allergic reactions to hymenoptera stings. Clin Exp Allergy 1991, 2 I:28I-288

5. Valentine M, Schuberth K, Sobotka A, Graft D, Kwiterovich K, Szklo $M$, Lichtenstein $L:$ The value of immunotherapy with venom in children with allergy to insect stings. $N$ Engl J Med 1990, 323:1601-1603

6. Golden DB, Marsh DG, Kagey-Sobotka A, Freidhoff L, Szklo M, Valentine MD, Lichtenstein LM: Epidemiology of insect venom sensitivity. JAMA 1989, 262:240-244

7. McGain F, Harrison J, Winkel KD: Wasp sting mortality in Australia. Med J Aust 2000, 173:198-200

8. Molina C: Acquisitions récentes sur l'allergie aux hyménoptères. Immunol médicale 1985, 10:67-7|

9. Reisman R: Insect stings. N Engl J Med 1994, 33 1:523-527

10. Rueff F, Reissig J, Przybilla B: Side effects of rush hyposensitization with hymenoptera venoms. Allergo J 1997, 6:59-64

II. Mueller HL: Insect allergy. Pediatr Clin North Am 1959, 6:917-952

12. Cohen SG: The pharaoh and the wasp. Allergy Proc 1989, I0:149I5|

13. Hunt KJ, Valentine MD, Sobotka AK, Benton AW, Amodio FJ, Lichtenstein LM: A controlled trial of immunotherapy in insect hypersensitivity. N Engl J Med 1978, 299:|57-161

14. Golden DB, Schwartz HJ: Guidelines for venom immunotherapy. J Allergy Clin Immunol 1986, 77:727-728

15. Lockey RF, Turkeltaub PC, Olive ES, Hubbard JM, Baird-Warren IA, Bukantz SC: The Hymenoptera venom study. III: Safety of venom immunotherapy. J Allergy Clin Immunol 1990, 86:775-780

16. Mosbech H, Malling HJ, Biering I, Bowadt H, Soborg M, Weeke B, Lowenstein $\mathrm{H}$ : Immunotherapy with yellow jacket venom. A comparative study including three different extracts, one adsorbed to aluminium hydroxide and two unmodified. Allergy 1986, 41:95-103

17. Bousquet J, Muller UR, Dreborg S, Jarisch R, Malling HJ, Mosbech $\mathrm{H}$, Urbanek $R$, Youlten L: Immunotherapy with Hymenoptera venoms. Position paper of the Working Group on Immunotherapy of the European Academy of Allergy and Clinical Immunology. Allergy 1987, 42:40 I-4I3

18. Reisman RE, Livingston A: Late-onset allergic reactions, including serum sickness, after insect stings. J Allergy Clin Immunol 1989, 84:331-337

19. Reisman RE, Livingston A: Venom immunotherapy: 10 years of experience with administration of single venoms and $50 \mathrm{mi}-$ crograms maintenance doses. J Allergy Clin Immunol 1992, 89:1189-1195

20. Reisman RE: Duration of venom immunotherapy: relationship to the severity of symptoms of initial insect sting anaphylaxis. J Allergy Clin Immunol 1993, 92:83 I-836 
21. Rueff F, Przybilla B, Muller U, Mosbech $\mathrm{H}$ : The sting challenge test in Hymenoptera venom allergy. Position paper of the Subcommittee on Insect Venom Allergy of the European Academy of Allergology and Clinical Immunology. Allergy 1996, 5 I:216-225

22. Laurent J, Smiejan JM, Bloch-Morot E, Herman D: Safety of Hymenoptera venom rush immunotherapy. Allergy 1997, 52:9496

23. Hoffman DR, Wood CL: Allergens in Hymenoptera venom XI. Isolation of protein allergens from Vespula maculifrons (yellow jacket) venom. J Allergy Clin Immunol 1984, 74:93-103

24. Valentine MD: Insect venom allergy: diagnosis and treatment. J Allergy Clin Immunol I 984, 73:299-304

25. Berchtold E, Maibach R, Muller U: Reduction of side effects from rush-immunotherapy with honey bee venom by pretreatment with terfenadine. Clin Exp Allergy 1992, 22:59-65

26. Westall GP, Thien FC, Czarny D, O'Hehir RE, Douglas JA: Adverse events associated with rush hymenoptera venom immunotherapy. Med J Aust 200 I, 174:227-230

\section{Pre-publication history}

The pre-publication history for this paper can be accessed here:

http://www.biomedcentral.com/1471-5945/2/11/prepub

Publish with BiolMed Central and every scientist can read your work free of charge

"BioMedcentral will be the most significant development for disseminating the results of biomedical research in our lifetime." Paul Nurse, Director-General, Imperial Cancer Research Fund

Publish with BMC and your research papers will be:

- available free of charge to the entire biomedical community

- peer reviewed and published immediately upon acceptance

- cited in PubMed and archived on PubMed Central

- yours - you keep the copyright 